TAP CHÍ KHOA HỌC ĐẠI HỌC TÂN TRÀO
ISSN: $2354-1431$

\title{
GÓP PHẦN TÌM HIỂU VĂN HÓA QUÂN SỰ HỒ CHÍ MINH
}

\author{
Nguyễn Hồ Thanh ${ }^{1 *}$ \\ ${ }^{1}$ Trưòng Đại học An Giang, ĐHQG-HCM \\ *Email: nhothanh@agu.edu.vn
}

\section{Thông tin bài viết}

Ngày nhận bài:

05/7/2020

Ngày duyệt đăng:

20/9/2020

Từ khóa:

Văn hóa quân sụ, văn hóa

quân sụ Hồ Chí Minh, Hồ Chí

Minh, tư tưởng Hồ Chí Minh.

\section{Tóm tắt}

Văn hóa quân sự Hồ Chí Minh là một bộ phận đặc biệt quan trọng trong nền văn hóa quân sự Việt Nam, gắn liền và xuất phát từ chính thực tiễn cách mạng của dân tộc Việt Nam trong thời kỳ Đảng ta lãnh đạo cách mạng. Bài viết khái quát văn hóa quân sự, nội dung văn hóa quân sự Hồ Chí Minh về bạo lực cách mạng, chiến tranh nhân dân, quốc phòng toàn dân, xây dựng lực lượng. Trên cơ sở đó, đề xuất một số định hướng trong giáo dục và nghiên cứu văn hóa quân sự Hồ Chí Minh trong thời gian tới.

\section{1. Đặt vấn đề}

Chủ tịch Hồ Chí Minh là lãnh tụ vĩ đại của cách mạng Việt Nam, là một nhà văn hóa lớn. Trên cơ sở kế thừa truyền thống văn hóa quân sự của dân tộc, trên nền tảng học thuyết quân sự của chủ nghĩa Mác Lênin, tiếp thu tinh hoa văn hóa quân sự của nhân loại, Chủ tịch Hồ Chí Minh đã góp phần đặc biệt quan trọng tạo nên sự khác biệt về chất cho nền văn hóa quân sự Việt Nam. Văn hóa quân sự Hồ Chí Minh là tài sản vô cùng quý giá của quốc gia, dân tộc. Đó là kết quả của tư duy sắc sảo, tâm đức lớn của Người trong quá trình tìm đường cứu nước, lãnh đạo, chỉ đạo tiến trình cách mạng Việt Nam. Việc tìm hiểu, vận dụng, bảo vệ và phát triển văn hóa quân sự Hồ Chí Minh là một nhiệm vụ nằm trong hệ thống hoạt động nghiên cứu về Chủ tịch Hồ Chí Minh của toàn Đảng, toàn quân và toàn dân ta.

\section{Nội dung văn hóa quân sự Hồ Chí Minh}

\subsection{Khái niệm về văn hóa quân sụ và văn hóa quân sụ̂ Hồ Chí Minh}

\subsubsection{Văn hóa quân sụ}

Văn hóa quân sự nói chung, văn hóa quân sự Việt Nam nói riêng, cũng là một loại hình văn hóa. Nó là một chi lưu của dòng sông văn hóa dân tộc, một nhánh văn hóa con nằm trong nền văn hóa mẹ, và cũng tương tự như các loại hình: văn hóa học đường, văn hóa gia đình, văn hóa thời trang, văn hóa ẩm thực...

Tuy nhiên, khi nói đến quân sự thường là người ta muốn nói đến nội dung đấu tranh vũ trang, tức nói đến những hành động bạo lực. Thế thì tại sao lại có thể đặt văn hóa và quân sự đứng chung để tạo thành cụm từ văn hóa quân sự. Đúng là trong chiến tranh, bắn giết, đốt phá là những việc làm tàn bạo, không phải là những hành động mang tính nhân văn nhưng khi xem xét động cơ nào buộc phải tiến hành chiến tranh, chiến tranh tiến hành theo phương pháp nào để ít tổn thương nhất đối với nhân dân, đối với kẻ thù đã hạ vũ khí... thì đấy lại là hành động của văn hóa và trong trường hợp như vậy, văn hóa quân sự không còn thuộc phạm trù quân sự nữa mà đã bước sang phạm trù văn hóa.

Từ đó, chúng ta có thể hiểu "văn hóa quân sự là một bộ môn khoa học, ở trong đó, lý luận chung về văn hóa học được sử dụng để nghiên cứu về một loại 
hình hoạt động của con người là đấu tranh vũ trang" và văn hóa quân sự Việt Nam là "mối quan hệ giữa người Việt Nam với thực tiễn đấu tranh vũ trang chống ngoại xâm để từ đó chọn ra những phương pháp hành động thích hợp và hiệu quả nhằm đi tới chiến thắng nhưng lại mang theo một dấu ấn riêng” [1, tr. 15].

Như vậy, văn hóa quân sự có thể hiểu chung nhất là tổng hòa những dấu ấn sáng tạo và nhân văn nảy sinh từ tổ chức và hoạt động quân sự tiến bộ, cách mạng, kết tinh thành hệ thống giá trị chân, thiện, mỹ, phản ánh sự phát triển trình độ con người trong lĩnh vực quân sự của đời sống xã hội; có tác động thúc đẩy sự phát triển của lĩnh vực quân sự và đời sống xã hội theo xu hướng cách mạng, tiến bộ, nhân văn.

\subsubsection{Văn hóa quân sụ Hồ Chí Minh}

Nghiên cứu văn hoá quân sự Hồ Chí Minh là vấn đề quan trọng, không những khẳng định sự đóng góp về mặt thế giới quan và phương pháp luận mácxít về văn hoá độc đáo mà còn góp phần khẳng định giá trị hiện thực văn hoá quân sự của Người đối với sự nghiệp đấu tranh cách mạng của quốc gia - dân tộc Việt Nam trong thời đại mới. Có thể nói, trong quá trình lãnh đạo cách mạng Việt Nam, Chủ tịch Hồ Chí Minh đã có những kiến tạo kiệt xuất, đặt cơ sở cho nền quân sự cách mạng của dân tộc Việt Nam. Đó là hệ lý luận và chỉ đạo của Chủ tịch Hồ Chí Minh về xây dựng và vận hành nền quân sự cách mạng, nền quân sự giải phóng dân tộc và bảo vệ Tổ quốc, nền quân sự nhân dân mà ra và vì nhân dân. Mặc dù Chủ tịch Hồ Chí Minh không để lại một tác phẩm lý luận chuyên khảo nào về văn hoá quân sự, song có đầy đủ cơ sở để khẳng định trong lĩnh vực tổ chức và hoạt động quân sự của cách mạng Việt Nam, Người luôn đặt ra đòi hỏi rất cao và khắt khe là quân sự phải hướng tới sự sáng tạo và nhân văn, lấy nhân văn, nhân đạo làm điểm tựa, mục tiêu phấn đấu cho mọi tổ chức và hoạt động quân sự.

Văn hoá quân sự Hồ Chí Minh là một bộ phận hợp thành chỉnh thể thống nhất giữa bản chất chính trị cách mạng và tinh thần nhân văn, nhân đạo sâu sắc của Người. Chủ tịch Hồ Chí Minh là một nhà văn hoá lớn, không những cống hiến trọn đời cho sự nghiệp giải phóng dân tộc Việt Nam mà còn là biểu tượng cho sự kết nối mạch nguồn văn hoá Việt Nam từ truyền thống đến hiện đại và hơn thế là hướng tới tương lai.

Nhà báo Giăng Lacutuya (Giăng Lacutuya là một nhà báo tư sản Pháp đã từng đến Việt Nam 10 lần trong khoảng thời gian từ tháng 11 năm 1945 đến tháng 10 năm 1972) đã viết về Chủ tịch Hồ Chí Minh rằng: "Người làm nên lịch sử phi thường này đã hồi phục một dân tộc, xây dựng một quốc gia, điều khiển hai cuộc chiến tranh về cơ bản là những cuộc chiến tranh của các dân tộc bị áp bức. Cuộc chiến đấu chống Pháp mà ông lãnh đạo đã dẫn tới sự sụp đổ của một đế chế thuộc địa lớn. Cuộc chiến đấu mà ông đang tiến hành chống Mỹ như ông tin tưởng - nhất định thắng lợi - đang đánh dấu những giới hạn của sức mạnh kỹ thuật trước con người.

Trong tất cả những người đáng kính trọng, ông Hồ có lẽ là người đã chứng minh một cách giỏi nhất rằng: Một ý chí được vũ trang bằng kỹ thuật cầm quyền không sao chê trách được, đâm chồi bén rễ trong nguyện vọng nhân dân...” [3, tr. 25].

Cái "giới hạn sức mạnh kỹ thuật trước con người" mà Giăng Lacutuya đề cập có lẽ không có gì khác hơn là văn hóa quân sự Việt Nam được tích hợp đến đỉnh cao ở Chủ tịch Hồ Chí Minh và sự tỏa sáng, thấm sâu từ văn hóa quân sự của Người vào thực tiê̂n cách mạng giải phóng dân tộc Việt Nam trong thế kỷ XX. Chủ tịch Hồ Chí Minh không chỉ là nhà hoạt động thực tiễn trong sự nghiệp xây dựng nền văn hoá Việt Nam mới mà còn là nhà lý luận có những kiến giải sâu sắc, toàn diện mang tính triết lý về văn hoá và văn hoá quân sự của dân tộc.

Như vậy, từ tiếp cận bản chất văn hoá quân sự, văn hóa Hồ Chí Minh và nghiên cứu thực tiễn hoạt động lãnh đạo cách mạng, nhất là trực tiếp lãnh đạo sự nghiệp xây dựng nền quân sự cách mạng Việt Nam của Người trong thời đại mới, có thể hiểu: Văn hóa quân sự Hồ Chí Minh là một bộ phận cấu thành văn hóa Hồ Chí Minh, gồm tổng thể những sáng tạo hàm chứa giá trị chân, thiện, mỹ từ mục tiêu, tính chất, nội dung, phương thức tổ chức, hoạt động quân sự, nghệ thuật quân sự,... được phản ánh ở nhận thức, quan điểm, tư tưởng, hoạt động lãnh đạo, chỉ đạo đấu tranh cách mạng và quan hệ giao tiếp, ứng xử của Người trong lĩnh vực quân sự.

Văn hóa quân sự Hồ Chí Minh được hình thành, phát triển trong sự tác động tổng hợp của những điều kiện khách quan, chủ quan nhất định, bao gồm: truyền thống văn hóa quân sự của dân tộc Việt Nam, tinh hoa văn hóa quân sự nhân loại và chính từ sự trải nghiệm thực tiễn, phẩm chất nhân cách Hồ Chí Minh.

2.2. Cơ sở hình thành, phát triển văn hoá quân sụ̂ Hồ Chí Minh

Văn hóa quân sự Hồ Chí Minh được hình thành, phát triển trong sự tác động tổng hợp của những điều kiện khách quan, chủ quan: 


\subsubsection{Truyền thống văn hóa quân sự của dân tộc}

Trải qua hàng ngàn năm dựng nước và giữ nước, dân tộc Việt Nam đã tạo lập nên một nền văn hóa phong phú với những truyền thống tốt đẹp, cao quý, trong đó có truyền thống văn hóa quân sự. Các giá trị truyền thống dân tộc là một trong những cơ sở, nguồn gốc quan trọng góp phần hình thành văn hóa quân sự Hồ Chí Minh.

Truyền thống tốt đẹp, bản sắc văn hóa quân sự Việt Nam được Chủ tịch Hồ Chí Minh tiếp nhận, tích hợp cùng với kế thừa tinh hoa văn hóa nhân loại, trực tiếp nhất là quan điểm chủ nghĩa Mác - Lênin về văn hóa, chiến tranh, quân đội và từ thực tiễn đấu tranh cách mạng trên thế giới đã tạo nên nền móng của sự hình thành, phát triển văn hóa cách mạng Hồ Chí Minh, trong đó bao hàm văn hóa quân sự của Người.

\subsubsection{Tinh hoa văn hóa quân sụ nhân loại}

Trên hành trình tìm đường cứu nước, Chủ tịch Hồ Chí Minh luôn chủ động học tập, tiếp thu các giá trị văn hóa của nhân loại. Cùng với nghiên cứu, tiếp nhận giá trị trong tư duy quân sự của các nhà quân sự, chính trị nổi tiếng của phương Đông, Chủ tịch Hồ Chí Minh còn thâu thái, tích hợp của các nhà khai sáng ở phương Tây.

Chủ tịch Hồ Chí Minh đặc biệt quan tâm đến việc tiếp cận, nghiên cứu lý luận chủ nghĩa Mác - Lênin, trong đó có học thuyết chiến tranh và quân đội. Đây là cơ sở trực tiếp, có ý nghĩa quyết định đến sự hình thành, phát triển văn hóa quân sự Hồ Chí Minh, cả chiều sâu và tư tưởng cách mạng của Người.

\subsubsection{Tù trải nhiẹm thưc tiễn và phẩm chất nhân} cách Hồ Chí Minh

Chủ tịch Hồ Chí Minh là một trong số ít lãnh tụ chính trị trên thế giới có sự trải nghiệm thực tiễn đấu tranh cách mạng và hoạt động quân sự sôi nổi, phong phú trong một không gian rộng lớn với thời gian dài. Sự trải nghiệm của Người trong đời sống xã hội, trong hoạt động lãnh đạo cách mạng và chiến tranh chống xâm lược của nhân dân Việt Nam là cơ sở thực tiễn trực tiếp tác động đến sự hình thành, phát triển văn hóa quân sự của Người.

Để có thể học tập kinh nghiệm, khám phá và chiếm lĩnh tri thức, giá trị của các nền văn hóa lớn trên thế giới, Chủ tịch Hồ Chí Minh đã khổ công học tập thông thạo nhiều ngoại ngữ, chấp nhận và chủ động vượt qua mọi khó khăn, gian khổ, hiểm nguy để sống, để học và làm cách mạng. Ở Người hội tụ nhiều mẫu người, từ người lao động chân tay đến nhà trí thức, nhà chính trị, nhà quân sự, nhà văn, nhà báo, nhà thơ, chủ tịch đảng, chủ tịch nước... Chủ tịch Hồ Chí Minh là nhà tư tưởng lỗi lạc, nhà văn hóa lớn của nhân dân Việt Nam và là một trong những lãnh tụ chính trị vĩ đại của thế kỷ XX.

\subsection{Khái quát một số nội dung văn hóa quân sụ Hồ Chí Minh}

Văn hóa quân sự Hồ Chí Minh có thể được khái quát ở một số nội dung cơ bản:

2.3.1. Văn hóa quân sụ Hồ Chí Minh mang tính chính nghĩa, tự vệ, bảo vệ nhân dân, của nhân dân, vì nhân dân.

Giữ vững quyền tự do và độc lập là mục tiêu xuyên suốt thể hiện tính nhân đạo, nhân văn của tư tưởng quân sự Việt Nam trong thời đại Hồ Chí Minh. Mục tiêu ấy nhận thức ngày càng đầy đủ, sâu sắc và cụ thể trong từng thời kỳ cách mạng. Mục tiêu bảo vệ vững chắc độc lập, chủ quyền, thống nhất, toàn vẹn lãnh thổ của Tổ quốc thể hiện tính chất nhân văn của đường lối chiến tranh cách mạng Việt Nam do Chủ tịch Hồ Chí Minh lãnh đạo, là sự kế tục tinh thần yêu chuộng hòa bình nhưng biết cầm súng giữ gìn hòa bình khi có kẻ rắp tâm cướp nước, lật đổ chế độ chính trị, phá hoại cuộc sống bình yên của dân tộc.

Với ý chí bất khuất giành lấy hòa bình, thống nhất, độc lập và dân chủ ở Việt Nam, nhân dân Việt nam quyết đánh bại bất cứ kẻ thù xâm lược nào, đồng thời Việt Nam ủng hộ, đồng tình với tất cả những cuộc đấu tranh chống xâm lược và bảo vệ hòa bình trên thế giới. Chủ tịch Hồ Chí Minh đã khẳng định: “Chiến tranh có thể kéo dài 5 năm, 10 năm, 20 năm hoặc lâu hơn nữa, Hà Nội, Hải Phòng và một số thành phố, xí nghiệp có thể bị tàn phá, song nhân dân Việt Nam quyết không sợ! Không có gì quý hơn độc lập, tự do. Đến ngày thắng lợi, nhân dân ta sẽ xây dựng lại đất nước ta đàng hoàng hơn, to đẹp hơn!” [6, tr. 131]. Hay "Nhân dân Việt Nam chúng tôi rất yêu chuộng hòa bình, một nền hòa bình chân chính trong độc lập và tự do thật sự" [6, tr. 602].

Trong hai cuộc kháng chiến chống thực dân Pháp và đế quốc Mỹ xâm lược, Đảng ta và Chủ tịch Hồ Chí Minh luôn chủ trương tiến hành kháng chiến trước hết là để bảo vệ nhân dân. Đó là mối quan tâm lớn trong chỉ đạo chiến lược, chiến dịch, trong tổ chức chiến đấu của các đơn vị lực lượng vũ trang. Cách mạng Việt Nam từ năm 1930 đến năm 1975 chủ yếu là khởi nghĩa và chiến tranh cứu nước với đường lối và phương pháp cách mạng thấm đượm chủ nghĩa nhân văn Hồ Chí 
Minh. Chủ tịch Hồ Chí Minh bao giờ cũng nêu cao tinh thần chính nghĩa của cách mạng, lấy đó làm ngọn cờ hiệu triệu quần chúng nhân dân. Đó là mục tiêu giải phóng dân tộc, đem lại độc lập thống nhất cho đất nước, tự do, hạnh phúc cho nhân dân. Tư tưởng của Người đã trở thành nền tảng để đảng ta xác định đường lối cách mạng Việt Nam trên lĩnh vực quân sự, quốc phòng.

\subsubsection{Văn hóa quân sự Hồ Chí Minh thể hiện tính} nhân văn, nhân đạo cao cả trong sủ dụng bạo lự cách mạng

Chủ tịch Hồ Chí Minh từ rất sớm đã chỉ ra: "Trong cuộc đấu tranh gian khổ chống kẻ thù của giai cấp và của dân tộc, cần dùng bạo lực cách mạng chống lại bạo lực phản cách mạng, giành lấy chính quyền và bảo vệ chính quyền" [6, tr. 391]. Văn hóa quân sự Hồ Chí Minh phản ánh rõ bạo lực vũ trang không phải là mục tiêu mà chỉ là một hình thức đấu tranh để thực hiện mục tiêu cách mạng là giành và giữ nền độc lập dân tộc, nhân dân được sống trong hòa bình, trong độc lập, tự do, xây dựng cuộc sống ấm no, hạnh phúc.

Đối với Chủ tịch Hồ Chí Minh đấu tranh vũ trang, chiến tranh cách mạng là việc bất đắc dĩ, việc cầm súng chiến đấu cũng là để bảo vệ hòa bình - một nền hòa bình thực sự, hòa bình trong độc lập, tự do để giải phóng giai cấp, giải phóng dân tộc, giải phóng xã hội, giải phóng con người. Chủ tịch Hồ Chí Minh chỉ rõ: "Nhân dân Việt Nam đã bị chính sách vũ lực, chính sách xâm lăng của một vài người đại diện Pháp ở Đông Dương xô đẩy vào một cuộc chiến tranh tự vệ thảm khốc" và "chính sách vũ lực mà các nhà đại diện Pháp ở Đông Dương vẫn áp dụng từ trước tới nay, đã bó buộc dân tộc Việt Nam phải võ trang tự vệ" $[3$, tr. 76].

Với Chủ tịch Hồ Chí Minh, việc sử dụng bạo lực cách mạng chống lại bạo lực phản cách mạng để giành và giữ chính quyền là một tất yếu lịch sử đối với các dân tộc bị áp bức dưới chế độ thực dân, đế quốc. Sự phát triển sáng tạo của Chủ tịch Hồ Chí Minh là ở chỗ Người đã chỉ ra bạo lực cách mạng là bạo lực của quần chúng nhân dân có tổ chức và được rèn luyện trong đấu tranh cách mạng dưới sự lãnh đạo của Đảng Cộng sản. Bạo lực cách mạng là sự kết hợp của nhiều biện pháp, cách thức đấu tranh về quân sự, chính trị, kinh tế, ngoại giao, văn hóa... mà có thể khái quát trong hai hình thức cơ bản chủ yếu là đấu tranh chính trị và đấu tranh vũ trang; kết hợp sử dụng hai lực lượng là lực lượng chính trị của quần chúng và lực lượng vũ trang nhân dân để đập tan bộ máy cai trị của bọn đế quốc, tay sai, giành chính quyền về tay nhân dân. Lực lượng vũ trang kết hợp với lực lượng chính trị, đấu tranh vũ trang kết hợp với đấu tranh chính trị, đó là hình thức cơ bản của bạo lực cách mạng Việt Nam.

Bạo lực cách mạng trong văn hóa quân sự Hồ Chí Minh hàm chứa sâu sắc tính nhân văn, nhân đạo. Người cho rằng chính sự hung bạo, dã man, sự nô dịch, thống trị của kẻ thù buộc người cách mạng phải sử dụng bạo lực để thực hiện quyền tự vệ chính đáng và xa hơn, cao hơn là thực hiện mục tiêu giải phóng dân tộc, giải phóng con người.

\subsubsection{Văn hóa quân sự Hồ Chí Minh thể hiện rõ ý} chi quyết tâm chiến đấu chống ngoại xâm

Chủ tịch Hồ Chí Minh thể hiện rõ ý chí kiên quyết chống ngoại xâm đến cùng. Người đã nêu cao ý chí: Hễ còn một tên lính thực dân trên đất nước Việt Nam, thì Việt Nam cứ đánh, đánh cho đến thắng lợi hoàn toàn, đánh cho đến độc lập và thống nhất thật sự. Với một niềm tin sắt đá, Người khẳng định dù thực dân Pháp hay đế quốc Mỹ, quân và dân ta kiên quyết kháng chiến để giành thắng lợi hoàn toàn. Quyết tâm chính trị đó cũng chính là khát vọng của cả dân tộc Việt Nam. Là người cầm lái vĩ đại, suốt cuộc đời cách mạng của mình, Chủ tịch Hồ Chí Minh đã dẫn dắt nhân dân ta quyết tâm thực hiện bằng được nguyện vọng chính đáng của Nhân dân ta, của dân tộc ta.

Người chỉ rõ: "Giônxơn và bè lũ phải biết rằng: Chúng có thể đưa 50 vạn quân, 1 triệu quân hoặc nhiều hơn nữa để đẩy mạnh chiến tranh xâm lược ở miền Nam Việt Nam. Chúng có thể dùng hàng nghìn máy bay, tăng cường bắn phá miền Bắc. Nhưng chúng quyết không lay chuyển được ý chí sắt đá, quyết tâm chống Mỹ cứu nước của nhân dân Việt Nam anh hùng" [6, tr. 131]. Ý chí sắt đá của Chủ tịch Hồ Chí Minh và của Đảng ta quyết tâm chống ngoại xâm đã hun đúc quyết tâm của toàn dân ta quyết đánh, quyết thắng giặc trong bất cứ tình huống nào, đó không phải là một quyết tâm chủ quan phiêu lưu mạo hiểm mà là một quyết tâm mang tính cách mạng và khoa học sâu sắc.

Ý chí quyết tâm chiến đấu chống ngoại xâm trong văn hóa quân sự Hồ Chí Minh là sản phẩm của sự kết hợp tinh thần triệt để cách mạng của giai cấp công nhân, truyền thống kiên cường bất khuất của dân tộc và khoa học của chủ nghĩa Mác - Lênin, là sản phẩm của sự thống nhất cao độ giữa nhân tố chủ quan và 
quy luật khách quan của thời đại. Văn hóa quân sự Hồ Chí Minh luôn thể hiện tinh thần lạc quan vào thắng lợi của cách mạng, tin tưởng chắc chắn vào sự nghiệp cách mạng của nhân dân nhất định sẽ thắng lợi, bởi vì "chúng ta đoàn kết chặt chẽ, toàn dân một lòng, cho nên chắc chắn rằng chúng ta cũng nhất định thắng lợi” $[3$, tr. 89].

\subsubsection{Văn hóa quân sụ Hồ Chí Minh thực hiện} đường lối tiến hành chiến tranh nhân dân Việt Nam toàn dân, toàn diện, kháng chiến lâu dài

Xuất phát từ tư tưởng lấy dân là gốc, có dân là có tất cả, quán triệt quan điểm của chủ nghĩa Mác Lênin về vai trò quần chúng nhân dân trong đấu tranh cách mạng, Chủ tịch Hồ Chí Minh khẳng định: Trong hoạt động quân sự và đấu tranh vũ trang, xây dựng lực lượng vũ trang, "phải dựa vào dân, không được xa rời dân" [5, tr. 270], khơi nguồn sức mạnh cho dân, tổ chức tập hợp và đoàn kết toàn dân tạo nên sức mạnh to lớn chiến thắng kẻ thù.

Thực tiễn chiến tranh ở Việt Nam cho thấy, kẻ thù xâm lược thường mạnh hơn ta về tiềm lực kinh tế, quân sự,... Do vậy, về phía ta, để chiến thắng các đạo quân nhà nghề, được trang bị kỹ thuật hiện đại thì không thể chỉ dựa vào lực lượng vũ trang, quân đội mà phải dựa vào lực lượng toàn dân, tổ chức tập hợp và phát động toàn dân đứng lên đánh giặc cứu nước. Văn hóa quân sự Hồ Chí Minh là văn hóa chiến tranh nhân dân, toàn dân, toàn diện, lâu dài, tự lực cánh sinh, dựa vào sức mình là chính, đồng thời ra sức tranh thủ sự giúp đỡ cả về tinh thần, vật chất của bè bạn, nhân loại tiến bộ. Chiến tranh nhân dân trong văn hóa quân sự Hồ Chí Minh luôn gắn với toàn diện. Sức mạnh của chiến tranh nhân dân Việt Nam theo quan điểm của Chủ tịch Hồ Chí Mỉnh, của Đảng ta là sức mạnh tổng hợp trên tất cả các mặt quân sự, chính trị, kinh tế, văn hóa, ngoại giao.

Trong kháng chiến chống thực dân Pháp xâm lược, kế thừa kinh nghiệm truyền thống của dân tộc, Chủ tịch Hồ Chí Minh nói: "Tổ tiên ta đời Trần, vì già trẻ một lòng trường kỳ kháng chiến, mà đánh tan giặc Nguyên. Nay chúng ta cũng già trẻ một lòng, trường kỳ kháng chiến, chúng ta nhất định sẽ đánh tan giặc Pháp" [4, tr. 517]. Trong cuộc kháng chiến chống Mỹ, cứu nước, Chủ tịch Hồ Chí Minh vẫn tiếp tục khẳng định quan điểm đánh lâu dài. Trong Di chúc, Chủ tịch Hồ Chí Minh nhấn mạnh tính lâu dài của cuộc kháng chiến: "Cuộc kháng chiến chống Mỹ có thể sẽ kéo dài mấy năm nữa. Đồng bào ta có thể phải hy sinh nhiều của nhiều người. Dù sao, chúng ta phải quyết tâm đánh giặc Mỹ đến thắng lợi hoàn toàn ” $[6$, tr. 612$]$.

Quan điểm đó của Chủ tịch Hồ Chí Minh là nhằm phát huy sức mạnh cao nhất và sự nỗ lực của các yếu tố chủ quan trên cơ sở của sự hiểu biết, nắm chắc sự vận động của khách quan. Cách mạng Việt Nam phát triển theo quy luật như vậy. Phương châm chiến lược đánh lâu dài của chiến tranh nhân dân Việt Nam không phải là thụ động, trông chờ vào sự yếu đuối của địch, mà đó là quá trình chủ động tiến công để đánh lùi từng bước, đánh bại từng âm mưu, thủ đoạn của địch đi tới đánh bại ý chí của kẻ xâm lược.

\section{Thay lời kết}

Văn hóa quân sự Hồ Chí Minh rất phong phú, bao trùm trên nhiều lĩnh vực, từ quan điểm về bạo lực cách mạng, chiến tranh nhân dân, quốc phòng toàn dân, xây dựng lực lượng vũ trang nhân dân... đến khoa học nghệ thuật quân sự Việt Nam. Văn hóa quân sự Hồ Chí Minh là một cơ sở có ý nghĩa trực tiếp hình thành đường lối quân sự của Đảng Cộng sản Việt Nam, chỉ đạo xuyên suốt trong mọi thời kỳ, mọi lĩnh vực, mọi mặt của hoạt động quân sự trong cách mạng dân tộc dân chủ nhân dân, trong chiến tranh giải phóng và chiến tranh bảo vệ Tổ quốc.

Việc tăng cường truyền bá nâng cao nhận thức văn hóa quân sự Hồ Chí Minh cho toàn thể nhân dân hiện nay là một đòi hỏi rất cấp thiết. Đây là vấn đề rất quan trọng tạo cơ sở trực tiếp để phát huy giá trị văn hóa quân sự Hồ Chí Minh cho người dân Việt Nam. Việc phát huy giá trị quân sự Hồ Chí Minh góp phần đặc biệt quan trọng trong xây dựng ý thức bảo vệ Tổ quốc Việt Nam. Trong điều kiện hiện nay cần tập trung thực hiện tốt một số vấn đề:

Một là, trong điều kiện cho phép, đưa nội dung văn hóa quân sự Hồ Chí Minh vào các chương trình giáo dục, tuyên truyền cho các đối tượng phù hợp với yêu cầu.

Hai là, gắn giáo dục văn hóa quân sự Hồ Chí Minh với giáo dục văn hóa quân sự dân tộc.

Ba là, tổ chức nghiên cứu một cách có hệ thống văn hóa quân sự Hồ Chí Minh, văn hóa quân sự dân tộc. Phát huy kết quả nghiên cứu vào sự nghiệp xây dựng và bảo vệ Tổ quốc Việt Nam xã hội chủ nghĩa trong tình hình mới. 


\section{REFERENCES}

1. Duong Xuan Dong (2011), Vietnamese military culture with sincere, benevolent and beautiful purposes, Journal of Culture and Arts, No. 330, December 2011.

2. Nguyen Manh Huong (editor) (2005), Ho Chi Minh Thought on the All-People Defense, People's Army Publishing House, Hanoi.

3. Assoc.Prof.Dr. Nguyen Van Huu (editor) (2018), Learn about Ho Chi Minh's military culture, National Political Publishing House, Hanoi.
4. Ho Chi Minh (2011), Completed Works, p.5, Hanoi National Political Publishing House.

5. Ho Chi Minh (2011), Completed Works, Vol.7, Hanoi National Political Publishing House.

6. Ho Chi Minh (2011), Completed Works, Vol.15, Hanoi National Political Publishing House.

7. Institute of Social Science for Military Humanities (2014), Vietnam National Defense Thought, People's Army Publishing House, Hanoi.

\section{CONTRIBUTING TO RESEARCH HO CHI MINH MILITARY CULTURE}

\section{Article info}

Recieved:

05/7/2020

Accepted:

20/9/2020

Keywords:

military culture, Ho Chi Minh military culture, Ho Chi Minh, Ho Chi Minh's ideology.

\begin{abstract}
Ho Chi Minh's military culture is a particularly important part of Vietnam's military culture, closely linked to and derived from the revolutionary practices of the Vietnamese nation during the period when the Party led the revolution. The article outlines military culture, the content of Ho Chi Minh military culture on revolutionary violence, people's war, national defense, and building forces. On that basis, propose some orientations in Ho Chi Minh military education and cultural research in the coming time.
\end{abstract}

